\title{
Michel Wasserman, D'or et de neige. Paul Claudel et le Japon
}

\section{Simonetta Valenti}

\section{(2) OpenEdition \\ 1 Journals}

\section{Édition électronique}

URL : http://journals.openedition.org/studifrancesi/7015

DOI : 10.4000/studifrancesi.7015

ISSN : 2427-5856

Éditeur

Rosenberg \& Sellier

\section{Édition imprimée}

Date de publication : 1 septembre 2010

Pagination : $402-403$

ISSN : 0039-2944

\section{Référence électronique}

Simonetta Valenti, « Michel Wasserman, D'or et de neige. Paul Claudel et le Japon », Studi Francesi [En ligne], 161 (LIV | II) | 2010, mis en ligne le 30 novembre 2015, consulté le 08 janvier 2021. URL : http:// journals.openedition.org/studifrancesi/7015; DOI : https://doi.org/10.4000/studifrancesi.7015

Ce document a été généré automatiquement le 8 janvier 2021.

\section{(c) $(1) \&$}

Studi Francesi è distribuita con Licenza Creative Commons Attribuzione - Non commerciale - Non opere derivate 4.0 Internazionale. 


\title{
Michel Wasserman, D'or et de neige. Paul Claudel et le Japon
}

\author{
Simonetta Valenti
}

\section{RÉFÉRENCE}

MICHEL WASSERMAn, D'or et de neige. Paul Claudel et le Japon, Paris, Gallimard, 2008, pp. 232.

1 Le volume de Michel Wasserman rend compte du séjour japonais de Paul Claudel, qui couvrit les années comprises entre 1921 et 1927. Claudel avait désiré ardemment être affecté au Japon, avant que sa première destination en qualité de Consul général de France ne lui ouvre les portes du Céleste Empire, l'assignant définitivement en $1902 \mathrm{au}$ poste de Shanghai, où il demeura environ quinze ans. Ce ne fut en effet que le 10 janvier 1921 que Claudel reçut la notification de sa nomination au grade d'ambassadeur à Tokyo.

2 Au cours de son séjour au Japon, Claudel se trouva face à une nation désormais élevée au rang de puissance internationale, c'est pourquoi la mission du poète-diplomate se déclina essentiellement suivant deux lignes directrices: la première, de teneur nettement politique, visa à ouvrir le plus possible le marché japonais à la France, en promouvant les échanges avec la voisine colonie indochinoise; la deuxième, de valeur décidément plus culturelle, avait pour but de diffuser la littérature et la langue françaises au Japon, et déboucha sur la fondation de la Maison franco-japonaise (mars 1924).

Or, au niveau de la production poétique et théâtrale de Claudel, le séjour japonais coïncida avec l'accomplissement de cette véritable summa du théâtre claudélien qu'est Le Soulier de Satin. Par ailleurs, le contact avec la tradition théâtrale japonaise - tout particulièrement avec le nô et le kabouki - constitue un moment essentiel de la réflexion dramaturgique claudélienne qui tendra depuis à intégrer la présence du chœur, ayant la fonction de commenter l'action, non seulement à travers des dialogues lyriques, mais aussi à travers le chant. 
4 En outre, la rencontre avec la culture japonaise joua un rôle essentiel dans la rédaction du recueil de poèmes publié par Claudel en 1927 chez l'éditeur Koshiba de Tokyo sous le titre: Cent phrases pour éventails. Composée de 172 poèmes calligraphiés par le poète, chacun desquels est accompagné de deux idéogrammes, cette œuvre manifeste l'influence de la littérature japonaise, et plus généralement orientale, à deux niveaux: tout d'abord, Claudel tire explicitement son inspiration du haiku, sans pour autant céder à une imitation acritique de la forme brève qui caractérise ce genre poétique; deuxièmement, il reprend pour ainsi dire à son bien la tradition idéographique de l'Extrême-Orient, en agençant des textes qui se présentent comme de véritables dialogues entre un poème français, écrit de sa main, et deux caractères chinois tracés par le peintre Arishima Ikuma, qui en proposent une sorte de cristallisation.

5 Loin de représenter une simple parenthèse dans la brillante carrière du poètediplomate, le séjour japonais de Claudel constitue donc, d'après Wasserman, la dernière phase de la réflexion poétique et dramaturgique que cet auteur n'a cessé d'alimenter tout le long de sa vie. 